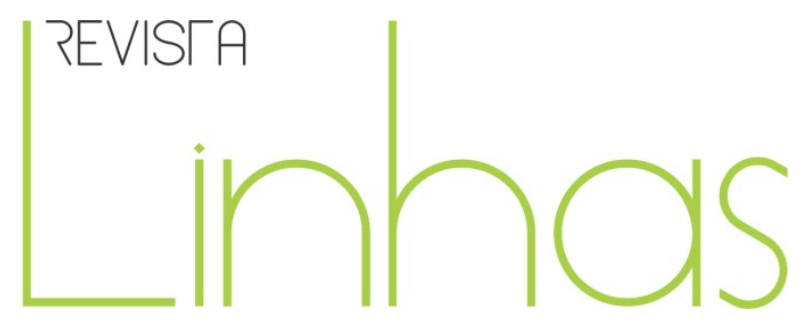

\title{
Educação de mulheres em revista: currículo, gênero e consumo
}

\section{Resumo}

Os meios de comunicação contribuíram para a alteração de valores, identidades e ideais almejados. Em maio de 2012, a revista TPM (Trip para Mulheres) propôs uma série de reportagens, colunas e entrevistas que discutem e questionem os estereótipos femininos disseminados pelas publicações femininas. Com o slogan "Se liberdade é ser a mulher que você quer ser, diz aí: você é livre?", a publicação discute padrões e modelos de maternidade, moda, consumo, beleza, sexo, comportamento e outras caracterizações que fixam o ideal de feminino transmitido em diversas instituições sociais, culturais e políticas, entre elas, a escola e as mídias. Nossa questão norteadora é: de que modo são tratados os discursos inscritos na temática de moda e beleza que evidenciam o consumismo? Com base nas teorizações feministas e foucaultianas, analisamos as possibilidades de engendrar nos currículos as discussões acerca da igualdade de gênero e desacomodar os discursos de consumismo explorados pela mídia. Selecionamos três textos inscritos na proposta do manifesto publicado no site da TPM com o intuito de verificar a existência dos estereótipos que caracterizam a mulher. Analisamos as informações discutidas pelos entrevistados e colunistas que visualizam valores, ideias, modelos femininos e apontam os produtos relacionados ao ideal de beleza. Os discursos desse veículo de comunicação explicitam padrões e fornecem outras leituras e perspectivas sobre a relação beleza/consumo/felicidade, oportunizando olhares sobre o feminino e o masculino como históricas, sociais, culturais e políticas.
Teresa Kazuko Teruya

Doutora em Educação pela

Universidade Estadual Paulista Júlio de Mesquita Filho Unesp/Marília

Professora do Departamento de Teoria e Prática da Educação e do Programa de Pós-Graduação da Universidade Estadual de Maringá - UEM

tkteruya@gmail.com

\section{Samilo Takara}

Doutorando em Educação pela

Universidade Estadual de Maringá - UEM

Bolsista Capes/Fundação Araucária sami.takara@gmail.com

Palavras-chave: Educação; Currículo; Mídia; Cultura; Gênero.

\section{Para citar este artigo:}

TERUYA, Teresa Kazuko; TAKARA, Samilo. Educação de mulheres em revista: currículo, gênero e consumo. Revista Linhas, Florianópolis, v. 15, n. 28, p. 279-301, jan./jun. 2014. 


\title{
Education of women in review: curriculum, gender and consumption
}

\begin{abstract}
The media have contributed to the change of values, identities and ideals pursued. In May 2012, the TPM (Trip for Women) proposed a series of reports, columns and interviews to discuss and to question female stereotypes disseminated by publications female. With the slogan "If freedom is to be the woman you want to be, says there: you are free?", The publication discusses patterns and models of motherhood, fashion, consumer, beauty, sex, behavior and other characterizations that secure the ideal female transmitted in various social institutions, cultural and political, between them, the school and the media. Our guiding question is: how are they treated the speeches included in the theme of fashion and beauty show consumerism? Based on Foucault and feminist theorizing, analyzing the possibilities of engendering curricula discussions about gender equality and dislodge the discourses of consumerism exploited by the media. Selected three texts included in the proposed manifesto published in the journal TPM in order to verify the existence of stereotypes that characterize the woman. We analyze the information discussed by the interviewees and columnists who see values, ideas, female models and point products related to beauty ideal. The discourse of explicit communication vehicle standards and provide additional readings and perspectives on the relationship beauty / consumer / happiness, providing opportunities perspectives on the feminine and masculine as historical, social, cultural and political.
\end{abstract}

Keywords: Education; Curriculum; Media; Culture; Gender. 
As mídias ensinam outras formas de "ver, ler, escrever e entrar em contato com outro universo cultural". Essas possibilidades são aspectos que fomentam a educação dos sujeitos. As tecnologias de informação e comunicação alteraram os modos de viver no mundo e seus usos são possibilidades de entrar em contato com diferentes perspectivas culturais. Entretanto, não devemos ser ingênuos quanto aos discursos emitidos pelos meios de comunicação. O excesso de informações disponibilizadas nas mídias torna-se um obstáculo à "nossa capacidade de conceituar, pensar e estabelecer relações dialéticas para a compreensão da realidade social” (TERUYA, 2009, p. 156).

Difusores de discursos, esses artefatos culturais oportunizam o acesso a diferentes informações e colaboram para a produção de conhecimentos e saberes. As mídias no espaço escolar podem evidenciar temáticas que perpassam as noções de gênero e sexualidade. Concordamos que "o silêncio e o segredo significam uma tomada de posição ao lado de quem detêm a autoridade e a legitimidade. Quando se está numa guerra, a omissão sempre favorece o dominante" (LOURO, 2000, p. 56-57). Destacamos a mídia como artefato no currículo escolar que oportuniza espaços de educação do olhar para a leitura dos estereótipos de gênero e sexualidade, a fim de problematizar os discursos que constroem as culturas e o consumo que atendem aos interesses mercantis (TERUYA, 2009; SABAT, 2001).

Os discursos nos formatos de notícias, reportagens, entrevistas, crônicas e outros textos são emitidos como verdades. As mídias, portanto, são territórios de discussões sobre política, economia, cultura, educação, sociedade e também sobre comportamentos. O consumo dessas informações insinua às mulheres e aos homens maneiras de pensar o que é importante para diferentes públicos.

Nossa análise baseia-se nos Estudos Culturais, caracterizados por Cevasco (2008, p. 60) como um eixo para discussões polêmicas que se distancia das "direções consagradas". A autora destaca a dificuldade de restringir essas outras perspectivas ofertadas por esse eixo axiológico. Entendemos a mídia e a cultura como campos em 
disputa de poderes e saberes, constituindo provisoriamente batalhas que delimitam contornos de verdades. As discussões culturais são imprescindíveis para a educação dos sujeitos e a constituição de uma condição equânime, com base na rica perspectiva que esses estudos propõem ao se inscreverem nas perspectivas dos movimentos sociais e aderirem ao slogan feminista “o pessoal é político".

Ao sublinharem a particularidade dos sujeitos e subjetividades, as feministas expuseram a constituição de um ser "abstrato, universal, racional, reflexivo" preso a uma característica masculina constituída historicamente. A exaltação do privilégio aos brancos oriundos da cultura eurocêntrica é uma contribuição dos estudos sobre raça e etnia. Esses movimentos nos aproximam da compreensão de que "não existe sujeito ou subjetividade fora da história e da linguagem, fora da cultura e das relações de poder" (SILVA, 2009, p. 9-10).

Como ressalta o autor, a subjetividade humana se encontra em uma reorganização de ruínas e não são mais proposições para toda uma vida. A liberdade de expressão e de escolha, o consumo e o discurso capitalista de "tecnologia" contribuíram para que homens e mulheres, para além da fragmentação de suas identidades, tornassem suas escolhas descartáveis e pouco cuidadosas. Para fazer escolhas significativas é necessário que os sujeitos sejam formados para a análise e percebam-se como pertencentes do processo social de produção de informações, bem como de discursos que valorizem as diferenças na sociedade. Desse modo, Silva (2011, p. 88) argumenta que o currículo universitário - e poderíamos estender a todos os currículos - precisa "incluir uma amostra que fosse mais representativa das contribuições das diversas culturas subordinadas".

Embasados pela discussão do autor, entendemos que os currículos são seleções de conhecimentos autorizados para os espaços escolares e acadêmicos. Os discursos das produções femininas, as possibilidades de outros olhares ficaram excluídas do currículo educacional, como destaca Santomé (2008, p. 163), aceitar a “própria identidade é uma das principais condições para saber valorizar a dos demais". O autor discute que as instituições de ensino não analisam as formas de opressão com atenção prioritária e não discutem questões relacionadas às diferenças culturais por estarem envolvidas em uma 
compreensão dicotômica entre bom e mau. Para ele, faz-se necessário analisar os discursos dominantes, como os propagados pelas mídias, para desconstruirmos estereótipos de gênero, raça, classe entre outros.

É preciso que as instituições escolares sejam lugares onde se aprenda, mediante a prática cotidiana, a analisar como e por que as discriminações surgem, que significado devem ter as diferenças coletivas e, é claro, individuais. É necessário que todo o vocabulário político que faz parte da evolução democrática de uma sociedade, ou seja, como poder, justiça, desigualdade, luta, direitos não se converta num vocabulário academicista, referido a contextos históricos e espaciais distantes, longe da vida cotidiana de nossa sociedade. (SANTOMÉ, 2008, p. 176-177, grifos do autor)

Concordamos com o autor e recorremos às contribuições de Sibilia (2008, p. 16) para discutir as modificações nos processos de subjetividade ao pensarmos em uma educação que considera as culturas negadas no currículo. Segundo a autora, diversos vetores são aplicados sobre corpos e subjetividades: "socioculturais, econômicos e políticos". Suas forças implicam em sujeitos de diversos espaços e tempos. Então como compreendemos a subjetividade? A autora nos oferece uma definição como possibilidades de se distanciar "de toda essência fixa e estável que remete ao 'ser humano' como uma entidade a-histórica de relevos metafísicos, seus contornos são elásticos e mudam ao sabor das diversas tradições culturais".

A subjetividade não seria então uma entidade que "reside 'dentro", mas sim as modulações possíveis da interação com os outros e com o mundo que produzem experiências. As mudanças em valores, pensamentos e modos de agir no mundo estão relacionadas intimamente com as possibilidades de contato com outros sujeitos e as ações históricas que alteram o "campo de experiência subjetiva” (SIBILIA, 2008, p. 16). Somos sujeitos em desenvolvimento. As práticas, as construções, as ciências e todas as ações humanas estão em movimento como nossas identidades e as sociedades.

É por não termos uma fixação que se faz necessário entender e adquirir métodos para analisar os discursos midiáticos dispersos em nossas sociedades. Afinal, os dispositivos de poder que são gerados e geridos em diversas instâncias sociais e culturais buscam captar as produções feitas pelos sujeitos e transformá-las em produtos. As 
marcas sugerem a construção de subjetividades que estão cercadas pelo consumo desenfreado e pelas imposições do mercado. Atitudes, valores e ideais tornam-se também bens, produtos e serviços a serem consumidos (KELLNER, 2004; SIBILIA, 2008).

Embasados na concepção de currículo como "o conjunto de conteúdos previstos para serem ensinados, organizados/estruturados segundo uma lógica determinada" (GALLO, 2004, p. 38), vislumbramos essa lógica produzida na Modernidade e o papel desse currículo, para este autor, é visto ainda como "imagens de currículo [...] relacionadas com certas concepções de conhecimento". Questionamos os conhecimentos considerados próprios da escola. Nessa direção, o nosso trabalho está intimamente ligado à concepção de bricolage apresentada por Nelson, Treichler e Grossberg (2008) como estratégia dos Estudos Culturais. Discutir e problematizar os discursos das mídias são questões curriculares e formam identidades, práticas e processos que estão presentes em nossa sociedade do espetáculo, do consumo e das culturas. Desse modo, não separamos o currículo das práticas pedagógicas e da formação de professores e professoras, mas defendemos um olhar que é plural e que vislumbra as mídias e seus discursos como agentes de um currículo escolar.

Os sujeitos, cada vez mais consumidores de discursos, denotam o poder-saber que está disperso em nossas sociedades. Uma leitura analítica e aprofundada das estereotipias e das proposições ofertadas pelos meios de comunicação desarticula as identidades rígidas construídas na modernidade. Nesse momento histórico, encontramos outras possibilidades de construir uma condição equânime às mulheres e aos homens e outras diferenças que foram caladas pelos discursos normativos dos séculos anteriores. A escola, o currículo e as mídias são espaços para problematizar as performances de gênero. São artefatos que produzem as performances consideradas adequadas e, no caso dos veículos de comunicação, inserem essas possibilidades na lógica do consumo. 


\section{Revista para mulheres: análises possíveis}

Em maio de 2001, a Editora Trip lança uma versão para as mulheres, com o slogan “TPM - uma revista que não trata a mulher como idiota. Tem público, né?”. Localizamos suas publicações disponíveis no site da revista. Seu discurso se contrapõe "às revistas tradicionais, acusadas de ofender a inteligência e autoestima das mulheres" (HOLLENBACH, 2005, p. 64). A revista TPM coloca em primeiro plano "o cultivo da alma e em atividades que lhe tragam prazer" e em segundo plano a "vida amorosa e sexual" das leitoras, explicitando que as mulheres são "pessoas inteligentes, com interesses diversificados, ousadas, livres e fortes - o que não as tornaria menos bonitas e femininas" (HOLLENBACH, 2005, p. 114-115).

A TPM trata de assuntos ligados a cultura, música, cinema, moda, culinária e decoração, em uma perspectiva diferente das revistas femininas que tradicionalmente foram popularizadas nos diferentes mercados e disponíveis na internet. Hollenbach (2005, p. 114-115) afirma que a ideia desta revista é endereçada àquelas que "em vez de desperdiçar seu tempo pensando em estratégias para agarrar um homem, elas vão a mostras de arte, viajam pelo interior do País e lugares exóticos no exterior e praticam esportes radicais".

[...] ao entender como a revista TPM representa o corpo, pode-se refletir sobre os conhecimentos produzidos acerca do corpo e seus significados. Além disso, é possível inferir quais as mudanças e quais as permanências ocorridas em relação às representações de gênero. Essas inferências podem ser realizadas considerando-se que o corpo tipifica os gestos, as formas estéticas e os comportamentos caracterizados como femininos e masculinos. Cristalizam-se no corpo as crenças, as representações e os significados do que é ser homem ou mulher em determinada sociedade, em determinado momento. (MATOS; LOPES, 2008, p. 61-62)

As autoras destacam a contribuição das análises acerca da noção de corpo na revista e explicam que a TPM é estruturada de uma forma que editoriais e reportagens movimentam-se a cada edição. São fixos alguns elementos como as Páginas Vermelhas; Ensaio (sensual); Editorial de Moda; Eu, tu, eles; dicas de livros, filmes, decoração e viagens e colunas de opinião. Matos e Lopes (2008) destacam 3 delas: Casa da Chris, Um 
pensamento e a Coluna do Meio. Esses textos trabalham com informações sobre comportamento, beleza, moda, decoração, artefatos culturais, ensaios sensuais masculinos. Mesmo afirmando-se em outra ordem discursiva, como destaca o slogan da revista, a TPM é uma publicação que também depende de seus anunciantes e segue a lógica de sua editora, a TRIP, que têm uma revista para o público masculino com o nome da editora e assemelha-se à estrutura apresentada (MATOS; LOPES, 2008).

Em maio de 2012, a revista lançou uma nova discussão, intitulada: “Você é livre?”. É um manifesto proposto pela TPM para discutir e problematizar "os novos clichês femininos e os velhos estereótipos, que cismam em reinventar desde o tempo de nossas avós"1. O discurso da revista é a defesa da autonomia para a mulher quebrar os estereótipos, oportunizar discussões e pensar sobre seu corpo e suas escolhas. Esse manifesto tem o intuito de desconstruir os estereótipos de corpo, comportamentos e ideais que são arraigados em nossa cultura e questiona algumas posturas valorizadas em nossa sociedade. Entretanto, essa publicação é mantida por anunciantes. Essas indicações de escolhas e de liberdade de expressão, em nosso entendimento, são cerceadas pelas marcas e valores dos produtos e serviços oferecidos em suas páginas.

Para analisar o movimento deste manifesto, selecionamos três textos relacionados à moda e consumo. Seguimos as proposições de Michel Foucault, (2009a; 2009b), amparados pelo apontamento de Oksala (2011, p. 7) sobre a intenção do filósofo em estarmos "dispostos a questionar a ordem social firmemente estabelecida, a abrir mão de todas as verdades petrificadas, agarrando-nos ao mesmo tempo a um frágil compromisso com a liberdade".

Foucault comparava seus livros como "caixa de ferramentas" em que os pesquisadores poderiam buscar auxílio às interpretações de diferentes discursos. Entre suas contribuições, destacamos a análise do poder produtivo - que colabora para o desenvolvimento de informações e discursos, no sentido de colaborar para uma produção de verdades - que organiza as relações sociais, culturais, políticas e econômicas. Desse modo, as inquietações foucaultianas balizaram as ações intelectuais e

\footnotetext{
O texto completo do Manifesto "Você é livre?" está disponível no site da revista http://revistatpm.uol.com.br/manifesto.
} 
políticas de grupos feministas e discussões acerca da psiquiatria, as opressões e as discussões sobre homossexualidade (OKSALA, 2011).

As contribuições de Foucault para as pesquisas em Gênero, Sexualidade e Educação estão relacionadas à compreensão de que "a filosofia não era um corpo de saber que se acumulava, mas um exercício crítico". Desse modo, cabe ao intelectual sugerir outros raciocínios e "perturbar seus hábitos mentais" no intuito de evocar e nutrir as necessidades de mudanças. Não seria o papel do filósofo ser uma "consciência moral da sociedade", seu papel é o de buscar liberdade e apontar outras possibilidades de pensamento (OKSALA, 2011, p. 14-15).

Os estudos de Foucault (2009b, p. 14) contribuem para analisar os discursos midiáticos. No discurso encontramos os rastros de uma "vontade de verdade" que denota proposições e compreensões inscritas em um mesmo discurso. Entendemos que a construção da verdade está imbricada no que o pensador denomina "sistemas de exclusão" que estão incrustados nos ditos.

Construímos as verdades por meio das exclusões impostas pelas instituições. Foucault (2009b, p. 17) sugere que as práticas sociais, no caso da pedagogia, a constituição dos livros, a formulação dos pensamentos, estão relacionadas ao saber delegados aos espaços autorizados como os laboratórios e as universidades. Assim, os pesquisadores movimentam as "vontades da verdade" pelos valorativos de nossa ciência ocidental cartesiana e atribuem uma maneira específica à distribuição e a repartição dos conhecimentos pela condução dos especialistas.

O exemplo dado por Foucault (2009b) é o da constituição do sistema penal. No século XIX foram produzidos discursos na Sociologia, na Psicologia, na Medicina, na Psiquiatria para validar as imposições do discurso jurídico. Precisamos nos atentar que as qualidades de "riqueza, fecundidade, força doce e insidiosa universal" que estão em torno da verdade não são as únicas características desses discursos. Devemos ter em vista, nos discursos emitidos que a "vontade da verdade" move uma "prodigiosa maquinaria destinada a excluir todos aqueles que, ponto por ponto, em nossa história procuraram contornar essa vontade de verdade e recolocá-la em questão contra a 
verdade" evidenciamos assim que existem interdições no discurso a fim de evitar questionamentos. Defender uma verdade compara-se ao papel do pesquisador explicitado por Foucault como aquele que deve pensar outros modos de raciocinar (FOUCAULT, 2009b, p. 20-21).

Recorremos às teorizações foucaultianas para analisar as relações entre os diferentes saberes e a instituição de poderes na formulação das verdades dispersadas pelas mídias. As relações tecidas não são internas nem externas ao discurso. Para além das ligações entre palavras e conceitos, há no limite do discurso "feixes de relações que os discursos devem efetuar para poder falar de tais ou tais objetos, para poder abordálos, analisá-los, classificá-los, explicá-los etc." Evidenciamos que o discurso como prática imbrica-se nas circunstâncias que o produzem e não na língua que se utiliza (FOUCAULT, 2009a, p. 51-52).

Cevasco (2008) utiliza das contribuições de Raymond Williams para compreender o conceito de cultura e desenvolver condições para que todos sejam produtores de cultura, ao invés de consumidores de uma cultura difundida por grupos que instituem seus saberes como verdades únicas. Assumir tal perspectiva significa render-se aos valores hegemônicos da cultura patriarcal. Desse modo, concordamos com Macedo (2010) de que a cultura é o que permite a identificação com o outro, pois os significados são compartilhados em determinado contexto.

Analisar os discursos midiáticos é apontar alguns desses significados que tecem os discursos de verdade e limitam o pensamento e a ação. Veiga-Neto (2009) ressalta que nos valer das teorizações foucaultianas sobre discursos e verdades e utilizá-las, não esquecemos de que o método é um caminho para delinear as percepções e compreensões sobre o objeto analisado. O autor compreende o método aludido por Foucault como o "caminho que é construído durante o ato de caminhar" (VEIGA-NETO, 2009,p. 88-89). De forma alguma, o método será seguro, previsível ou único. Os percursos não estão organizados em "pontos de saída" ou "pontos de chegada”, porque a constituição de uma pesquisa que se utiliza das colaborações de Foucault analisa e problematiza os discursos. 
Desse modo, constituímos nossa análise dos discursos midiáticos como possibilidades de desacomodar as verdades impostas, o machismo, o sexismo e os discursos hegemônicos que inferiorizam e desqualificam as ações de homens e mulheres em contextos sociais, culturais, políticos e econômicos. As mídias são artefatos culturais que proporcionam aos sujeitos o acesso às pedagogias culturais que conceituam, valorizam atitudes e posicionamentos para a validação de determinado estereótipo (FISCHER, 2001; SABAT, 2001; KELLNER, 2004, 2008; FURLANI, 2009; TERUYA, 2009, BELELI, 2010). Dessa forma, problematizamos as manutenções e as regulações dos discursos midiáticos no intuito de discutir as representações acerca das mulheres e das performances de feminilidades hegemônicas.

Defendemos a formação de sujeitos consumidores críticos dos discursos emitidos pela mídia para que saibam examinar a consistência das informações, dos modelos e dos padrões. A constituição da mulher proposta uma linha editorial da revista TPM contesta os padrões hegemônicos e combate os ideais machistas, sexistas e opressivas. De que modo essas reportagens abordam a feminilidade o consumo nas práticas femininas? Como explicitam as representações femininas? A TPM apresenta uma leitura crítica das ideias sobre o feminino e rompe com os padrões patriarcais.

Analisamos algumas proposições apresentadas nos discursos da TPM e na discussão política expressa na frase: “Você é livre?”, a fim de oportunizar as leitoras repensarem suas escolhas e seus comportamentos. Hollenbach (2005) analisa a redação do site TPM que relaciona jornalismo, humor e confissão de colunistas, editoras convidadas, repórteres e leitoras. O apelo aos discursos médicos, comum em outras publicações destinadas às mulheres, é diluído em algumas entrevistas e reportagens.

Para nossa reflexão sobre os discursos consumistas e possibilidades de leituras críticas selecionamos no site da Revista TPM três textos da seção Moda datados de 6 de junho de 2012: a reportagem Pra que tudo isso? e a entrevista Estilo Pensado assinadas pela jornalista Luciana Obniski e a coluna Tudo novo, de novo da mestra em Comunicação e pesquisadora Denise Gallo. Esses textos sugerem discussões sobre consumo, moda e corpos femininos. Os comentários de Alexandre Bergamo e Ted Polhemus, que são pesquisadores e entrevistados pela jornalista, visualizam outros contextos que a moda 
interfere nas relações sociais. O intuito é analisar os enunciados emitidos por esse veículo de comunicação que desacomodam os estereótipos femininos.

Com base nas percepções de Foucault quanto à historicidade e as culturas que marcam os corpos, Braga (2005) explicita que os produtos midiáticos instituem práticas e ações que configuram uma cultura do corpo promovida pela mídia. Os contornos atrelados ao consumo, à moda e as significações estáticas reinventam as culturas femininas.

Para compreender o mundo feminino nos textos que expressam enunciados sobre moda, consumo e feminilidades, destacamos a proposição editorial da TPM de desarticular os padrões e os estereótipos femininos. Nessa proposição, localizamos os discursos sobre o consumo na constituição das identidades femininas. De que modo esses discursos ensinam mulheres como agir e pensar sobre o consumo e a estética? Esses discursos corroboram para uma desarticulação do discurso de reificação do corpo da mulher?

Em nossa leitura, a recepção negociada das informações disponíveis nas mídias favorece a construção de conhecimentos que podem ser incluídos no currículo para problematizar os preconceitos e as condições equânimes de gênero, a fim de perceber as vivências e as experiências que perpassam nas publicações. A construção do currículo é uma seleção, portanto, na formação dos professores e das professoras é imprescindível que a construção dos conteúdos e suas seleções para o processo pedagógico englobem a justificativa de porque determinados conhecimentos são curriculares e outros não (SILVA, 2011).

As discussões de corpos em "alta performance", discutidos por Haraway (2009) e Kunzru (2009a), estão presentes nos discursos analisados. Nos apontamentos das produtoras dos textos reconhecem a relação entre os discursos do consumo, a moda e as produções do corpo. A pesquisadora Denise Gallo, em seu texto Tudo novo, de novo questiona alguns padrões rígidos, como o consumismo e a ansiedade provocados pelo mercado da moda, causando desconforto se não estiver de acordo com as suas tendências. Consumir diferentes esmaltes que definam uma identidade, que comuniquem 
o que deseja é uma das críticas feitas pela colunista. Os currículos escolares não apresentam questões relacionadas ao consumo como forma de expressão. Silenciado sobre a questão da construção do corpo e das características elencadas pela cultura do consumo como ideais de beleza, o espaço escolar não problematiza o significado desses artefatos para a construção das identidades que são produzidas nessas relações.

O foco do texto são as cores de esmaltes que o mercado brasileiro desenvolve no discurso das tendências. Esta pesquisadora ressalta a monetarização e a comercialização dos gostos e das vontades, utiliza o cifrão que significa dinheiro (\$) para o plural de tendência. O texto anuncia a utilidade das unhas que estão "protegendo seus dedos de machucados, aplacando coceiras, eventualmente arranhando algumas costas aqui e ali, em momentos mais inspirados" (GALLO, 2012) A colunista explicita um caráter de uso e como o valor das tendências resignifica os corpos. Para Kunzru (2009b), a informação favorece o processo de construção de corpos e as ações de perpassam as identidades de gênero. A mídia comunica treinamentos de ginástica, dietas, produtos e serviços que prometem o corpo ideal inscrito na ideia de um “corpo-máquina”, que Haraway (2009) apresenta estar ligado ao consumo e ao entendimento do corpo como produto. Os usos de esmaltes, roupas e acessórios estão identificados como uma necessidade para a inserção dos sujeitos na relação social.

Na entrevista intitulada Estilo Pensado da publicação em junho de 2012, na TPM, o antropólogo americano Ted Polhemus afirma que antigamente havia uma "ditadura da moda" que rotulava o que deveria ser usado. O antropólogo cita, por exemplo, o encurtamento das saias e a entrada do rosa como a cor da moda que foram algumas das imposições do mundo da moda e estimulada pelo mercado editorial e publicitário. Polhemus explica que hoje temos muitas tendências e que elas não têm uma linha comum.

Del Priori (2000, p. 9) afirma que o século XXI "vai imprimindo suas primeiras marcas" nos corpos femininos que se tornam fragmentados, recompostos e desenvolvem regulações de usos, normas e funções. As luvas que protegiam as mãos e as saias que eram compridas foram substituídas pelas minissaias e os esmaltes de unhas, destacando uma sensualidade e o "estímulo do desejo". Gallo (2012,) lembra que o 
espectro das cores ampliam em suas variações de tonalidades e os nomes dos esmaltes agora são "sensações ou apelos esquisitos" como "inveja boa”, “doce loucura”, "me belisca”, “me beija”.

A colunista Denise Gallo ressalta a característica efêmera dos mercados que se inscrevem na concepção de moda, para comparar o tempo de escrita do texto ao tempo em que as influências estéticas de diversas correntes e grupos culturais urbanos invadem as lojas e se tornam tendências. Cita a combinação de diversas cores nas unhas, ao invés de uma só, que é a tendência da próxima estação - Primavera-Verão/2013 - para compor desenhos geométricos no suporte que tem funções de coçar machucados, aplacar coceiras e arranhar costas, como citou no início do texto.

Essa colunista reafirma que o consumo desenfreado causado pelas tendências do mercado da moda é lucrativo para as empresas, entretanto, por vezes, não colabora para o bem-estar das consumidoras. Pelo contrário, cada tendência da moda gera nas mulheres a necessidade de um consumo desenfreado. A "febre do novo" é o motor da moda. São cores, cortes, formatos e ideias de vestir-se e apresentar-se. A colunista apresenta estas mudanças que impõem necessidades impostas pela sociedade e pelas mídias em "aprender e reaprender, visitar e revisitar, inventar e reinventar nossos looks, nossos corpos, nossas vidas" (GALLO, 2012).

A constituição do corpo feminino está presa ao olhar do outro. Este outro proporciona à mulher uma condição de ser "um sujeito de significação social” (SWAIN, 2001, p. 74), ou seja, um sujeito que conquista a validade social, cultural e política para ser a mulher aceita na sociedade patriarcal e machista que fixa preconceitos. A moda se utiliza desse argumento que é a sedução. Del Priori (2000) ressalta que essas transformações ocorreram com o despir da mulher no século XX. As mídias colaboraram para tal feito e incentivaram o corpo nu em público. Essa nudez está atrelada a produção de "corpos de alta performance" como podemos encontrar nas discussões de Haraway (2009), Kunzru (2009a, 2009b) e Silva (2009). Para Kunzru (2009a, 2009b), essa alta performance está ligada a uma necessidade de desenvolvimento do corpo para o rendimento como uma máquina. Essa relação está atrelada ao consumo de academias de 
ginástica, produtos estéticos e fármacos, que incentivam a busca incessante do ideal de beleza, contribuindo para alimentar o sistema capitalista.

Os discursos atrelados ao ideal de beleza, estética e saúde, diversos produtos e serviços tornam-se alternativas para um corpo próximo aos padrões ideais endereçados às mulheres. A moda apropria-se e torna-se produto dos discursos difundidos na mídia como um ideal de beleza. Academias de ginástica e malhação, produtos naturais, serviços relacionados aos cuidados com a pele, o peso e outros acessórios para obter o corpo desejado são oferecidos por um preço variado, a fim de conseguir um ideal saudável. Problematizar o consumo produzido pela estética mercadológica e a chamada vida saudável proporcionada por serviços e produtos específicos também é um eixo possível no espaço escolar. As disciplinas podem discutir valores, processos e práticas para questionar esse tipo de consumo que se naturalizado na prática social.

A estética relacionada ao corpo saudável está presa também aos discursos de medicalização que se constituíram no decorrer do século passado. Diferimos das nossas avós, pois "não nos preocupamos mais em salvar nossas almas, mas em salvar nossos corpos da desgraça da rejeição social”. (DEL PRIORI, 2000, p. 11). A libertação como discurso feminista foi corrompida pela mídia e pelo status cultural consumista. A visibilidade tornou-se para as publicações femininas "lutar, centímetro por centímetro contra a decrepitude fatal. Decrepitude, agora, culpada, pois o prestígio exagerado da juventude tornou a velhice vergonhosa".

Para antropólogo norte-americano, na entrevista Estilo Pensado, explicita que as marcas estão focadas na venda de ideias. Além dos apelos à juventude, a saúde e a beleza, são as marcas que prometem, em suas logomarcas, estilo, valores, crenças e sonhos. Usamos aquilo que acreditamos ser a marca do "nosso estilo". Nosso cuidado deve ser para que não estejamos cegos aos apelos consumistas. Todas as tendências apresentam diferentes estilos e vendem uma vida que não pode ser comprada: a ideal vida feliz e perfeita.

Para Gallo (2012), as lógicas que perpassam a moda, hoje, pragmáticas e importantes estão em diversas revistas prometendo em suas manchetes resolver todos 
os problemas. Mas, a pesquisadora evidencia que tanto o otimismo e quanto a autoconfiança deixaram escapar algo. E ressalta: “diante de um armário lotado, sentimos aquela sensação de que não há roupa para vestir”. Swain (2001, p. 69) explicita que os assuntos destinados ao público feminino como "sedução e sexo, família, casamento, maternidade e futilidades" estagnam discussões importantes ao público feminino.

Essa sensação de não ter o que vestir abordada na entrevista concedida por Alexandre Bergamo à Luciana Obniski (2012, s/p.) na matéria Pra que tudo isso? sobre as questões relacionadas à moda, tem o intuito de constituir os discursos de verdades construídos pela publicação. Ao trazer um especialista, pesquisador ou sujeito de experiência que testemunha ou discute determinado assunto, esses discursos ganham defesas, são reforçados por critérios de verdade relacionados aos que vivenciaram uma experiência e aos estudiosos das diversas áreas que se relacionam com a temática. No caso da análise do pesquisador Alexandre Bergamo, ele explicita que a moda valoriza o futuro e despreza o passado. Essa característica temporal está ligada, para o entrevistado, ao fato de que as "pessoas não querem correr o risco de se sentirem excluídas pelo que estão vestindo".

Essa negociação simbólica, para Bergamo, está atrelada aos discursos do consumo e do descartável que imperam em nossas mídias e sociedades. As duas entrevistadas ilustram para as leitoras como se sentem ao abrir o guarda-roupa. Enquanto para a primeira explicita o desejo era "ter uma costureira que eu mostrasse fotos de revistas e ela copiasse igual", para a outra consumidora conta que trabalha próxima a um shopping e faz escolhas ruins, mas leva as roupas. Mesmo ciente de que talvez use apenas uma vez por ano o casaco, a entrevistada disse que vale a pena porque ela gostou muito da peça.

Essa perfeição exigida da mulher faz com que ela não perceba a própria identidade, por isso busca nas mídias uma identificação, como uma maneira de se sentir pertencente ao mundo feminino (DEL PRIORI, 2000). As publicações femininas operam em discursos que estão baseados em discursos de consumo e medicalização. O equilíbrio exigido para as mulheres atingirem essa “perfeição desejada” é a tríade beleza-saúdejuventude. Cada um desses discursos sobre o corpo perfeito e as identidades atende a 
uma cultura consumista que idealiza o modelo de ser mulher reverberados na mídia. (DEL PRIORI, 2000, p. 14).

Enquanto a primeira entrevistada da reportagem diz que gasta até 800 reais em uma peça de roupa, a segunda diz consumir em média vinte peças por mês. Apesar dos gastos proporcionados pelo alto poder aquisitivo, as entrevistadas afirmam que não estão satisfeitas. O desejo de querer uma blusa ou outro acessório que não estão entre seus pertences é manifestado por essas entrevistadas. Bergamo explica para as leitoras que essa necessidade pela roupa certa colabora para construir uma insatisfação permanente. Swain (2001, p. 70) questiona a ideia de a mulher consumidora que movimenta os poderosos setores industriais investindo nas características 'naturais' femininas como a domesticidade, sedução e reprodução. Gallo (2012) propõe o ato de despir. "Despir-nos de ritmos que não são nossos, ansiedades emprestadas, prioridades que não importam mais”. Para um armário lotado, a colunista indaga o que guardamos mais guardamos nas gavetas, abrindo possibilidades de pensarmos no que é nosso e no que está sendo imposto às mulheres.

Com 250 peças, a terceira entrevistada da reportagem é apresentada por Obniski (2012,) referenciada no discurso como uma proposta mais cuidadosa de consumo. Essa entrevistada não frequenta shoppings e só entra em uma loja certa do que está procurando e se não encontra, não compra outra coisa. Atitude discursada pela Obniski (2012) como "racional" entre moda e consumo, a entrevistada faz duas grandes compras no ano, nas estações de verão e inverno e não gasta mais de mil reais em cada uma. Mesmo confidenciando que já se sentiu mal por não estar na moda em uma festa, ela afirma que não se desfez de um vestido que não estava no "comprimento" da moda, porque lhe caia bem e poderia voltar à moda.

Identificamos os sujeitos como produtores de significados em uma cultura como um território em disputa. Questionar os quebrar padrões de consumo ancorado no machismo patriarcal são oportunidades que o texto de Denise Gallo oferece como outra leitura sobre as características e as necessidades da "mulher". Os padrões estabelecidos e o consumo são discutidos no texto da TPM como uma "vontade da verdade" diferenciada das demais publicações femininas e ressaltada no manifesto "Você é livre?". 
Estar consciente dos discursos do consumo é, também, perceber que existem enunciados de produção de moda e corpos que prometem uma vida feliz às leitoras, sem sacrifícios e dificuldades. Como na vida narrada em comédias românticas, as publicações destinadas às mulheres também prometem ilusões. Maria Rita Kehl (2004) discute o fetichismo idealizado no corpo feminino. A moda é um mercado que captura a necessidade de "ser olhada". Os corpos e as roupas significam ascensão social. As intervenções cirúrgicas esculpem ossos, músculos, gorduras e silhuetas adornados com objetos diferentes a todo momento.

O antropólogo Ted Polhemus destaca que a marca pessoal entrou e reconfigurou os parâmetros da moda, agregando consumidores e consumidoras nas construções das personalidades. A marca política e transgressora dos punks e dos góticos corrompeu-se no mercado da moda e tratou de "personalizar" seus produtos para chamar a "atenção à diferença". O entrevistado ainda destaca que o global e o pessoal são características que pretendem se encontrar "misturadas" na moda. Com o objetivo de colaborar para construir nossa identidade, as marcas criam possibilidades de mostrar quem somos. 0 imperativo é um só: consuma!

As noções de currículo apresentadas por Silva (2011) nos embasam para pensarmos na dinâmica de uma analítica da verdade na leitura do currículo. Segundo o autor, a necessidade de discussão sobre as questões de gênero, discutidas pelas feministas causou mudanças na análise desses textos ao propor discussões sobre os currículos como uma oportunidade de problematizar as noções de feminilidade e masculinidade na construção do conhecimento.

$\mathrm{Na}$ formação de professores e professoras há necessidade de desconstruir o currículo e questionar os padrões hegemônicos para desestabilizar conceitos binários. Esse movimento de desconstrução e a indagação da ciência e da verdade instituída é uma produção de conhecimentos sobre as vivências e experiências femininas para projetar uma condição equânime de gênero (SILVA, 2012; LOURO, 2008; SWAIN, 2004)

Para Hardt (2004, p. 122-123), a escola "é um espaço razoavelmente legítimo para discutir a circulação dos discursos com os saberes e poderes que eles trazem consigo". 
Não devemos proclamar doutrinas aos/às alunos/as. Na visão desta autora, o potencial da educação para a formação de sujeitos críticos e analíticos dos discursos midiáticos está no conceito de resistência elaborado por Foucault. Na formação docente, os discursos não revelam realidades obscuras, mas as criam. Resistir é um ato de criar condições para a resposta ao complexo saber-poder que dissemina verdades instituídas pelos grupos hegemônicos.

Vislumbramos que a TPM, mesmo apresentando rarefações dos discursos acerca da mulher, ainda reverbera "padrões estéticos vigentes em nossa sociedade, onde a beleza ideal e os modos de se servir do corpo são constantemente reafirmados, especialmente pela mídia" (MATOS; LOPES, 2008, p. 73). Mais do que visíveis, os corpos e padrões estéticos dos veículos de comunicação são produtos para o consumo. Além da pretensa beleza saudável e ativa, as mídias apresentam produtos e serviços que garantem o resultado esperado: a felicidade de mulheres que não perceberam em seus corpos "fonte de sua significação" e não aprenderam o cuidado como possibilidade de ser, mas definiram o modo de cuidado que precisa para os padrões de beleza expostos pela mídia.

Oportunizar a inserção desses artefatos midiáticos para a discussão no espaço escolar possibilita que esses estereótipos e padrões endereçados a meninas e mulheres sejam questionados. O desconforto das verdades impostas pela mídia colabora para que esses discursos não sejam assumidos como sinônimo de felicidade. Os discursos midiáticos popularizam o padrão de beleza, tão cara ao público feminino e masculino que incute um ideal de consumo. Problematizar discursos, modelos, imagens e estereótipos padronizados possibilitam outras formas de ser e pensar.

\section{Considerações}

Ressaltamos a presença do consumismo na construção da representação do gênero feminino que caracteriza as reportagens selecionadas. Diferenciando-se de outras publicações destinadas ao público feminino que tendem a relacionar o consumo, a 
beleza, a juventude e a moda ao padrão da "mulher perfeita", a TPM propõe um caminho diferente para ser mulher. Aponta aspectos interessantes da moda, como uma indicação para a construção do estilo pessoal e questiona o consumo exacerbado atribuído às mulheres de nossa sociedade.

A revista publica o discurso de especialistas, de jornalistas e de entrevistadas que contam suas experiências, dizem o que pensam e como lidam com determinadas questões na temática da moda. Entretanto, ainda encontramos o consumo como um aspecto que caracteriza e ensina a mulher. Mesmo fugindo ao padrão de "manual”, essas reportagens apresentam modelos negativos e positivos para tratar do consumo, moda e beleza como padrões a serem seguidos.

Os discursos da TPM são pronunciados por diferentes sujeitos que têm determinadas vivências e experiências. A temática destacada nesse artigo é a moda e os padrões inseridos nesse mercado. E o que fazer? Ao pensarmos nesse material como um artefato cultural, visualizamos potencialidades de discussão sobre a construção do consumo e da representação cultural da beleza feminina e a oportunidade de desconstruir os discursos sobre frivolidades que são implicados sobre as mulheres para a educação.

Explicitar as relações de poder que este artefato registra é uma possibilidade de pensar em condições equânimes na educação de mulheres e homens. Tendo em vista o currículo como conhecimentos a serem trabalhados com os alunos e as alunas defendemos a presença das temáticas relacionadas à mídia e gênero para problematizar de que modo construímos nossas compreensões acerca das questões de feminilidade e masculinidade e o que as mídias sugerem que devemos consumir para pertencermos a determinadas performances de gênero. 


\section{Referências}

BELELI, lara. Gênero. In: MISKOLCI, Richard (Org.). Marcas da diferença no ensino escolar. São Carlos: Ed. UFSCAR, 2010. p. 45-74.

BRAGA, Adriana. Corpo e Agenda na Revista Feminina. Cadernos IHU idéias. ano 3. n. 40, . p.1-24, 2005Disponível em: <http://www.bocc.ubi.pt/pag/braga-adriana-corpo-veraoagendamento-corporal-na-imprensa-feminina.pdf >. Acesso em: 20/04/2012.

CEVASCO, Maria Elisa. Dez lições sobre estudos culturais. 2.ed. São Paulo: Boitempo, 2008.

DEL PRIORI, Mary. Corpo a corpo com a mulher: pequena história das transformações do corpo feminino no Brasil. São Paulo: SENAC, 2000.

FISCHER, Rosa Maria Bueno. Mídia e educação da mulher: uma discussão teórica sobre modos de enunciar o feminino na TV. Estudos Feministas. n.N. 2, p.586-599, 2001.

Disponível em: <http://www.scielo.br/pdf/ref/vgn2/8642.pdf>. Acesso em: 24 de abril de 2011.

FURLANI, Jimena. Representações da mulher e do feminino na mídia impressa brasileira: desconstruindo significados na Educação Sexual. In: PARANÁ, Secretaria de Estado da Educação. Sexualidade - cadernos temáticos da diversidade. Curitiba/PR: SEED, 2009, p.131-158.

FOUCAULT, Michel. A arqueologia do saber. 7.ed. Rio de Janeiro: Forense Universitária, 2009a.

FOUCAULT, Michel. A ordem do discurso: aula inaugural no Collège de France, pronunciada em 2 de dezembro de 1970. 19. ed. São Paulo: Loyola, 2009b.GALLO, Denise. Tudo novo de novo. Revista TPM. n. 121, 06/06/2012. Disponível em: <http://revistatpm.uol.com.br/revista/121/reportagens/tudo-novo-de-novo.html> Acesso em: 20/07/2012.

HARAWAY, Donna. Um manifesto para os Cybogs: ciência, tecnologia e feminismo socialista na década de 80. In: SILVA, Tomaz Tadeu da. Antropologia do Ciborgue: as vertigens do pós-humano. 2.ed. Belo Horizonte: Autêntica, 2009. p. 33-118.

HARDT, Lúcia Scheneider. Os fios que tecem a docência. (Tese), Universidade Federal do Rio Grande do Sul, Doutorado em Educação, Porto Alegre/RS, 2004. Disponível em: <http://hdl.handle.net/10183/5831>. Acesso em: 13/12/2010. 
HOLLENBACH, Gabriela Boemler. Sexualidade em revista: as posições de sujeito em nova e TPM. (Dissertação) - Universidade Federal do Rio Grande do Sul. Programa de PósGraduação em Comunicação e Informação, Mestrado em Comunicação e Informação Porto Alegre/RS, 2005.

KEHL, Maria Rita. Com que corpo eu vou? In: BUCCI, Eugênio; KEHL, Maria Rita. Videologias: ensaios sobre televisão. São Paulo: Boitempo, 2004. p. 174-179.

KELLNER, Douglas. A cultura da mídia e o triunfo do espetáculo. LíBERO São Paulo, ano VI - v. 6 - n. 11. p. 4-15, 2004.

KUNZRU, Hari. "Você é um ciborgue": um encontro com Donna Haraway. In: SILVA, Tomaz Tadeu da. Antropologia do Ciborgue: as vertigens do pós-humano. 2. ed. Belo Horizonte: Autêntica, 2009a. p.17-32.

KUNZRU, Hari. Genealogia do Ciborgue. In: SILVA, Tomaz Tadeu da. Antropologia do Ciborgue: as vertigens do pós-humano. 2. ed. Belo Horizonte: Autêntica, 2009b. p. 119-126.

LOURO, Guacira Lopes. Currículo, gênero e sexualidade. Porto: Porto Editora, 2000, 111 p.

LOURO, Guacira Lopes. Um corpo estranho: ensaios sobre sexualidade e teoria queer. 1. reimp. Belo Horizonte: Autêntica, 2008.

MACEDO, Elizabeth. A Cultura e a escola. In: MISKOLCI, Richard (Org.). Marcas da diferença no ensino escolar. São Carlos: EdUFSCar, 2010. p. 11-43.

MATOS, Auxiliadôra Aparecida; Lopes, Maria de Fátima. Corpo e gênero: uma análise da revista TRIP Para Mulher. Estudos Feministas. v. 16, n. 1. Florianópolis: UFSC, p. 61-76, 2008

NELSON, Cary; TREICHLER, Paula A.; GROSSBERG, Lawrence. Estudos Culturais: uma introdução. In: SILVA, Tomaz Tadeu da (org.). Alienígenas na sala de aula. 7. ed. Petrópolis/RJ: Vozes, 2008. p.7-20.

OBNISKI. Luciana. Pra que tudo isso?. Revista TPM. n. 121, 06/06/2012. Disponível em: <http://revistatpm.uol.com.br/revista/121/reportagens/pra-que-tudo-isso.html> Acesso em: 20/07/2012.

OBNISKI. Luciana. Estilo Pensado. Revista TPM. n. 121, 06/06/2012. Disponível em: <http://revistatpm.uol.com.br/revista/121/reportagens/estilo-pensado.html> Acesso em: 20/07/2012.

OKSALA, Johanna. Como ler Foucault. Rio de Janeiro: Zahar, 2011. 
SABAT, Ruth. Pedagogia cultural, gênero e sexualidade. Estudos Feministas. Florianópolis , v. 9, n. 1, p. 9-21, 2001.

SANTOMÉ, Jurjo Torres. As culturas negadas e silenciadas nos currículos. In: SILVA, Tomaz Tadeu (org.). Alienígenas na sala de aula. Uma introdução aos Estudos Culturais em Educação. 7. ed. Petrópolis: Vozes, 2008. p. 159-177.

SIBILIA, Paula. O show do eu: a intimidade como espetáculo. Rio de Janeiro: Nova Fronteira, 2008.

SILVA, Tomaz Tadeu. Nós, ciborgues - O corpo elétrico e a dissolução do humano. In: SILVA, Tomaz Tadeu da. Antropologia do Ciborgue: as vertigens do pós-humano. 2.ed. Belo Horizonte: Autêntica, 2009. p.7-1).

SILVA, Tomaz Tadeu da. Documentos de identidade: uma introdução às teorias do currículo. 3. ed. 2. reimp. Belo Horizonte: Autêntica, 2011.

SWAIN, Tania Navarro. Feminismo e recortes do tempo presente. São Paulo em Perspectiva. v. 15. n. 3, p. 67-81, 2001.

SWAIN, Tania Navarro. Intertextualidade: perspectivas feministas e foucaultianas. In: Labrys - estudos feministas. n. 5, 2004. Disponível em:

<http://www.tanianavarroswain.com.br/labrys/labrys5/textos/eubr.htm>. Acesso em: 24 abr. 2012.

TERUYA, Teresa Kazuko. Sobre Mídia, Educação e Estudos Culturais. In: MACIEL, Lizete Shizue Bomura; MORI, Nerli Nonato Ribeiro (Orgs). Pesquisa em educação: múltiplos olhares. Maringá: Eduem, 2009. p. 151-165.

VEIGA-NETO, Alfredo. Teoria e Método em Michel Foucault (im) possibilidades. Cadernos de Educação. n. 34, Pelotas: FaE/PPGE/UFPel, p. 83-94, 2009.

Recebido em: 27/06/2013 Aprovado em: $15 / 10 / 2013$

Universidade do Estado de Santa Catarina - UDESC Programa de Pós-Graduação em Educação - PPGE Revista Linhas Volume 15 - Número 28 - Ano 2014 revistalinhas@gmail.com 